\title{
Suicide mortality in second-generation migrants, Australia, 2001-2008
}

\author{
Chi-kin Law, Kairi Kolves \& Diego De Leo \\ Australian Institute for Suicide Research and Prevention \\ National Centre of Excellence in Suicide Prevention \\ WHO Collaborating Centre for Research and Training in Suicide Prevention \\ Griffith University
}

Correspondence:

Chi-kin Law, PhD

Australian Institute for Suicide Research and Prevention

Mt Gravatt Campus, Griffith University

176 Messines Ridge Road

Mt Gravatt, Queensland 4122, Australia

Phone: +61. 7. 37353381

Fax: +61.7. 37353450

Email: c.law@griffith.edu.au 


\section{Abstract}

\section{Purpose}

Generally, due to limited availability of official statistics on the topic, little is known about suicide mortality in second-generation migrants. A recent study from Sweden showed that these people could be at a high suicide risk. If a generalized phenomenon, this aspect would represent an important issue in suicide prevention. This paper aims to report the profile of second-generation migrants who died by suicide and the suicide risk differentials of secondgeneration migrants with other Australians.

\section{Methods}

Official suicide data from 2001 to 2008 were linked with State/Territory registries to collect information about the birthplace of the deceased's parents to differentiate migration status (first, second or third-plus generation). The profile and suicide risk of second-generation migrants were compared with other generations by logistic and Poisson regression.

\section{Results}

Suicide in second-generation migrants accounted for 811 cases (14.6\%). These tended to be represented by younger subjects, more often never married, compared to the other cases. Second-generation males aged 25-39 years tended to have a higher suicide risk than firstgeneration migrants, but the risk was lower when compared with the third-plus generation. Second-generation migrants aged $60+$ tended to have a lower suicide risk than firstgeneration migrants.

\section{Conclusion}

In Australia, second-generation migrants are not at a higher suicide risk compared to firstgeneration migrants or locals (third-plus-generation). In males aged 25-39, a lower suicide risk was found in second-generations compared to Australian born third generation, which may be explained by their more advantageous socioeconomic status and the flexibility and resources rendered by having grown up in a bicultural environment. The higher suicide rates found amongst older first-generation migrants requires further examination.

\section{Keywords:}

Second-generation migrant, suicide, Australia, prevention, inequality 


\section{Introduction}

The suicide mortality of the second generation of migrants, unlike that of the first generation migrants, which has been widely studied [8-10, 19, 24], has received very little attention. The limited research exploring suicide risk among second-generation migrants has been mainly attributed to the prevailing practices of death registration around the world, which rarely collect information about the country of birth $(\mathrm{COB})$ of parents of the deceased $[8,27]$. The only study focusing on suicide mortality of second generation migrants, from Sweden, indicated that they were at a greater risk of suicide than first generation migrants [18]. The authors suggested that this vulnerability might be attributable to their more adverse living conditions in Sweden compared to those of first-generation migrants [18]. The higher risk of suicide among second-generation migrants could also be explained by the intergenerational acculturation conflict model $[7,27,31]$. Specifically, many migrant families in Western countries are made up of relatively un-acculturated parents who were born in another country residing with their children who have spent most of their time and been educated in the host country. Children in migrant families may find themselves caught between the more traditional values that their parents encourage at home and the more individualistic Western values they are exposed to at school and in the media $[21,32,33]$. The difference between the level of acculturation exhibited by parents and that of younger family members (acculturation gap) can lead to intergenerational conflicts, family stress and decreased cohesion between parents and children in migrant families. This would consequently heighten the risk of suicide and other causes of death for acculturated youth $[7,11,27,31]$ and older migrants $[13,29]$. 
There has been a high rate of migration to Australia. In the 2011 Census, more than $27 \%$ of the population was born overseas, and a further $20 \%$ had at least one overseas-born parent [5]. Despite diversity in their origins, second-generation Australians often share the common experience of being bicultural, living with both their parents' heritage and the mainstream culture of the host country $[12,16]$. This paper aims to report on the socioeconomic and demographic characteristics of second-generation migrants in Australia who died by suicide between 2001 and 2008, and examine the suicide risk among different migrant generations.

\section{Data and methods}

Identification of research subjects

Migrant generation status was determined by the birthplace of the deceased and that of their parents [27]. First-generation migrants are residents of Australia who were born overseas. Second-generation migrants are Australian-born people living in Australia, with at least one overseas-born parent. Finally, third-plus generation migrants are Australian-born people whose parents were both born in Australia $[3,5,27]$.

\section{Settings}

Two geographically adjacent regions in south-eastern Australia - New South Wales (NSW) and the Australian Capital Territory (ACT) - were included in the study. These two regions have a complete set of digitalised records for all births and deaths to facilitate data linkage in identifying the COB of the parents of the suicide deceased. 


\section{Suicide mortality data source}

Mortality data were obtained from the National Coroners' Information System (NCIS). The NCIS is a national database maintained by the Victorian Institute of Forensic Medicine, providing relevant information about every death reported to a coroner in Australia since July 2000 (January 2001 for Queensland) [30]. Through an online interface, authorised researchers can access individual records of death. These contain information on sociodemographic data, cause of death, classification of case type and intent [30]. In this study, intent registered as "intentional self-harm" was used to identify suicide cases.

The NCIS only includes information related to the deceased, and not about their parents or relatives. To identify second and later generations, data had to be obtained from the Registry of Births, Deaths and Marriages of the two jurisdictions. A flow-chart of the data linkage procedure is shown in Figure 1.

To safeguard data privacy, all relevant files were stored in the investigator's computer and secured with a password lock to restrict any unauthorised access. Ethics approval of the project was granted by the Griffith University Human Research Ethics Committee (GU Ref No: CSR/02/10/HREC) and the Justice Human Research Ethics Committee (CF/12/14310).

\section{Statistical analyses}

Statistical analyses were performed using SPSS for Windows version 20.0. The characteristics of suicide cases by different migrant generations were summarised using 
descriptive statistics. Multinomial logistic regression analyses were used to test the profile difference between second-generation migrants and other migrant generations in terms of sex, age, marital status, economic activity, usual residence and suicide method used.

Suicide rates were calculated using only the population aged $15+$ years, due to the low migrant population and occurrence of suicide in the youngest age group (0-14 years) [19]. Population figures by country of birth (COB), $C O B$ of parents, sex and age group were derived from the 2006 Census of Population and Housing [4]. About 7.2\% of the population data $(n=493,000)$ had a missing value on their COB [4]. To replace the missing data with a probable value, imputation was used, and those with a missing COB were proportionately distributed into the 3 migrant generation groups based on the observed pattern of the remaining $92.8 \%$ of population with a known $\mathrm{COB}$. To examine suicide risk among the different groups, Poisson regression was used. The exponential of the regression coefficient ( $\beta$ ) represents the incidence risk ratio (IRR), which describes the multiplicative effect of the corresponding independent variable on the risk [14]. A significant IRR indicates that there was a significant difference in the suicide risk between second-generation migrants and other migrant generations after adjustment for age and region. For all statistical analyses, a p-value smaller than $5 \%$ was considered to be statistically significant.

\section{Results}

From 2001 to 2008 , 5,541 suicides were identified in the two selected jurisdictions (ACT and NSW), indicating an average rate of 10.1 suicides per 100,000 persons. Among the suicide cases, 1,481 (26.7\%) were by first-generation migrants, 811 (14.6\%) by second-generation 
migrants (i.e., either mother or father born outside Australia), and 2,536 (45.8\%) were thirdplus-generation Australians. Of the second generation migrants, $40.7 \%(n=330)$ had both parents born overseas, $24.3 \%(n=201)$ had their mother and $35.0 \%(n=280)$ had their father born overseas. The remaining 713 cases (12.9\%) lacked information to identify their migrant generation status and were excluded. They included 523 (9.4\%) locally-born cases with missing information on parents' COB and 190 (3.4\%) cases with missing information on their own COB (Figure 2).

\section{Characteristics of suicides by second-generation migrants}

The socioeconomic characteristics of suicides across different migrant generations are summarised in Table 1. Compared with first-generation migrants, suicides by the secondgeneration were more likely to be younger than 40 years $(O R=3.26, p<0.0001)$, never married $(O R=2.5, p<0.001)$ and unemployed $(O R=1.40, p=0.002)$. No significant sex difference was found between suicides by second- and first- generation migrants. Second-generation suicide deceased also showed considerable differences in terms of their socio-demographic profile compared to third-plus generation migrants. When compared with the third-plus-generation, suicides by the second-generation were more likely to be younger than 40 years $(O R=1.84, p=<0.0001)$ and never married $(O R=1.40, p<0.001)$. Analyses also showed that they were less likely to use firearms $(O R=0.68, p<0.001)$. No significant difference was found by sex and employment status between suicides by secondgeneration and third-plus generation migrants. 
Suicide risk ratios of second-generation migrants

Comparison between second-and first-generation migrants

In the Poisson regression analysis, it was found that the overall risk of suicide among second-generation migrants in the ACT and NSW were not significantly different from that of the first-generation over the study period (see Table 2). When separately analysed by age group and sex, a significantly higher rate of suicide was detected among second-generation males aged 25-39 at 21.4 per 100, $000(\operatorname{IRR}=1.230, p=0.014)$ when compared to firstgeneration migrants at 17.4. On the other hand, a lower risk of suicide was found among older second-generation males (aged $60+)$ at $13.1(\operatorname{IRR}=0.681, \mathrm{p}=0.004)$ and older secondgeneration females at $4.5(I R R=0.661, p=0.043)$ compared to their first-generation counterparts at 19.3 for older males and 6.8 for older females, respectively.

Comparison between second- and third-plus-generation migrants

Through Poisson regression analyses, the risks of suicide among second-generation migrants were also found not to be significantly different from that of the third-plus-generation (see Table 2). When separately analysed by age group and sex, second-generation males aged 25-39 years had a significantly lower risk of suicide at $21.4(\operatorname{IRR}=0.848, p=0.021)$, compared to the third-plus-generation at 25.3. No significant difference was found in other age or sex groups.

\section{Discussion}

The present analysis provides the first analysis of suicides in second-generation migrants in Australia. In contrast to earlier research findings from Sweden, which showed that second 
generation migrants had a higher risk of suicide than first-generation migrants and other Swedish-born persons during the period 1990-1998 [18], our analysis did not detect any significant difference in the risk of suicide between second-generation migrants and other migrant generations. Furthermore, in certain age groups, a lower suicide rate was observed compared to third or later generation migrants. It seems that the intergenerational acculturation conflict model may not be applicable to second-generation migrants in Australia. When comparing Australian results with the Swedish study, it is important to emphasise their different migration histories. Second-generation migrants in Australia generally have higher education levels, are more likely to be professionals with a higher income level and are less likely to be unemployed compared with the third-plus-generation $[3,20]$. It is possible that their higher socioeconomic status may be a protective factor, contributing to a lower risk of suicide among second-generation males aged 25-39 years compared with the third-plus-generation. In addition, the experience of second-generation migrants of growing up in a bicultural environment (that of the parents and the host, Australia) might provide a bigger repertoire of skills and different attitudes, rendering second-generation individuals (especially young adult males) more flexible and resilient.

Although having a lower risk of suicide than third-plus-generation migrants, our findings revealed that second-generation males aged 25-39 years had a higher risk of suicide compared with first-generation migrants. This pattern may be partially explained by the well-known "healthy migrant effect", which suggests that first-generation migrants would have a lower risk of suicide, as immigration policy tends to favour individuals with high resilience and good mental health $[18,24,28]$, which are protective factors of suicide. Additionally, changes in the ethnic composition of migrants during the last 30 years may 
also contribute to the lower rate of suicide among first-generation migrants. Since the 1970s, there has been a large influx of Asian migrants to Australia [19]. In Asia, pesticide ingestion is one of the most commonly used method of suicide [35]. Vulnerable individuals from these countries might have limited access to their traditional highly lethal means of suicide (pesticides). It could contribute to a reduction in suicides if they use a less lethal method $[17,23]$. Finally, there has been a dramatic reduction in suicide rate in NSW during the study period [22] and this epidemiological transition could have also influenced the difference in suicide rates among the first, second and third-plus generation migrants, especially for the age group (25-39) with highest rate of suicide.

Unlike younger working-aged males, our results found that older (over 60 years) secondgeneration migrants for both sexes had a lower risk of suicide compared with firstgeneration migrants. Closer examination of the suicide rates suggests that older firstgeneration migrants had relatively high suicide rates compared with other migrant generations. In fact, this age-specific vulnerability of older migrant people was also observed in previous studies on migrant suicides [6, 8-10, 25, 34]. Many older migrants may experience poverty and loneliness without the traditional support of family, and some are left 'childless' after their children move away for education or work [6, 25]. Further, older migrants may experience intergenerational conflicts due to different values and beliefs than their families and communities, which may also lead to a higher rate of suicide [29]. However, the specific pattern of suicide in first generation migrants is beyond the scope of this study. 


\section{Limitations}

The findings of this study should be interpreted in light of its limitations. First, ethnicity could be an important factor in suicide rates [15] and have an effect on the differences in suicide rates by migrant generations. However, as the question on country of birth of parents was replaced by asking whether a person's parents were born in Australia or overseas in 2001, detailed coding on parents' birthplace was not available to differentiate second-generation migrants by different ethnic background [2]. Unlike the situation reported by Hjern et al in Sweden [18], there has been a high level of ethnic intermarriage among individuals from different countries of origin in Australia [1], which has impeded the possibility of any further analysis to estimate the specific suicide rates by ethnicity and national origin of second generation migrants. There has been no specific investigation of suicide mortality and its associated factors in inter-ethnicity groups in Australia, a fact which would deserve further attention in future research.

Secondly, due to the complex nature of the process of data linkage with the state and territory Registers of Births, Deaths and Marriages, we managed to capture information on parents' birthplace only for the suicide deceased who were born within the two jurisdictions, which means $72.9 \%$ (9.4\% out of $12.9 \%)$ of suicide cases with missing migrant generation status, who were internal migrants born outside NSW and the ACT, could not be investigated further and were excluded. Inevitably, this resulted in an underestimation of the suicide risk in the second- and third-plus generations, and narrowed the risk difference of second-generation migrants compared with first generation migrants in the analysis. A limitation arising from missing values was also found in the population data, with $7.2 \%$ of census responses having no information on their $\mathrm{COB}$ in order to identify their migrant 
generation status [4], which may affect accuracy and robustness in estimating the suicide rate for each migrant generation group in the analysis.

In conclusion, the present study demonstrates that there was no significant difference in terms of risk of suicide between second-generation migrants and other migrant generations. This would indicate a process of acculturation that ends with amalgamation in Australia. These data are reflective of the current composition of migrants to Australia by country of birth (this composition has changed quite radically in the last thirty years, with unprecedented numbers Asians migrating to Australia [19].

\section{Acknowledgments}

The authors would like to thank Mr Les Gould from NSW Registry Births Deaths and Marriages and Ms Nardia Cassidy from the ACT Office of Regulatory Services - Births, Deaths and Marriages, who kindly provided the data necessary for our analysis and Dr Delaney Skerrett for his valuable comments and suggestions to improve the quality of the paper.

\section{Conflict of Interest statement}

On behalf of all authors, the corresponding author states that there is no conflict of interest. 


\section{References}

1. Australian Bureau of Statistics (2006) 4102.0 - Australian Social Trends, 2000. http://www.abs.gov.au/AUSSTATS/abs@.nsf/2f762f95845417aeca25706c00834efa/ c414ec2a595eb029ca2570ec000e2817! OpenDocument Access 6 August 2012

2. Australian Bureau of Statistics (2007) 2007.0 - Information Paper: Census of Population and Housing: ABS Views on Content and Procedures, 2011. http://www.abs.gov.au/AUSSTATS/abs@.nsf/0/EBED27034540D49DCA25737F00167 AAD?opendocument Accessed 20 December 2012

3. Australian Bureau of Statistics (2009) 2070.0 - A Picture of the Nation: the Statistician's Report on the 2006 Census, 2006. http://www.ausstats.abs.gov.au/ausstats/subscriber.nsf/LookupAttach/2070.0Public ation29.01.0911/\$File/20700 Australians.pdf Accessed 9 August 2012

4. Australian Bureau of Statistics (2012a) Data \& analysis: Table Builder http://www.abs.gov.au/websitedbs/censushome.nsf/home/tablebuilder?opendocu ment\&navpos=240 Access 9 August 2012

5. Australian Bureau of Statistics (2012b) 2071.0 - Reflecting a Nation: Stories from the 2011 Census, 2012-2013: Cultural Diversity in Australia.

http://www.abs.gov.au/ausstats/abs@.nsf/Latestproducts/2071.0Main\%20Features 902012\%E2\%80\%932013?opendocument\&tabname=Summary\&prodno=2071.0\&iss

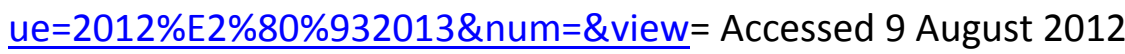

6. Baker FM (1994) Suicide among ethnic minority elderly: a statistical and psychological perspective. Geriatr Psychiatry 27: 241-264

7. Bourque $F$, van der Ven E, Malla A (2011) A meta-analysis of the risk for psychotic disorders among first- and second-generation immigrants. Psychol Med, 41: 897-910

8. Burvill PW (1998) Migrant suicide rates in Australia and in country of birth. Psychol Med, 28: 201-208

9. Burvill PW, McCall MG, Stenhouse NS, Reid TA (1973) Deaths from suicide, motor vehicle accidents and all forms of violent death among migrants in Australia, 196266. Acta Psychiatr Scand, 49: 28-50

10. Burvill PW, Woodings TL, Stenhouse NS, McCall MG (1982) Suicide during 1961-70 migrants in Australia. Psychol Med, 12: 295-308

11. De Leo D (2003) The interface of schizophrenia, culture and suicide. In Vijayakumar L (ed) Suicide Prevention: Meeting the Challenge Together. Orient Longman Private Limited, Chennai, pp.11-41 
12. Dennis J, Basanez T, Farahmandd A (2010). Intergenerational conflicts among Latinos in early adulthood: separating values conflicts with parents from acculturation conflicts. Hispanic J Behav Sci, 32(1): 118-135

13. Diego AT, Yamamoto J, Nguyen LH, Hifumi SS (1994) Suicide in the Elderly: Profiles of Asians and Whites. Asian Am Pac Isl J Health, 2(1): 49-57

14. Dunteman GH, Ho MHR (2004) An Introduction to Generalized Linear Models: Poisson Regression. Thousand Oaks, CA: Sage.

15. Durkheim E (1897) Le Suicide. Trans. J. H. Spalding \& G. Simpton (1951). New York: Free Press.

16. Giguere B, Lalonde R, Lou E (2010) Living at the Crossroads of Cultural Worlds: The Experience of Normative Conflicts by Second Generation Immigrant Youth. Soc. Personal Psychol. Compass, 4: 14-29, 10.1111/j.1751-9004.2009.00228.x

17. Hawton K, Townsend E, Deeks J, Appleby L, Gunnell D, Bennewith O, et al. (2001) Effects of legislation restricting pack sizes of paracetamol and salicylate on selfpoisoning in the United Kingdom: before and after study. BMJ, 322: 1203-1207

18. Hjern A, Allebeck P (2002) Suicide in first- and second-generation immigrants in Sweden A comparative study. Soc Psychiatry Psychiatr Epidemiol, 37: 423-429

19. Ide N,Kơlves K, Cassaniti M, De Leo D (2012) Suicide of first-generation immigrants in Australia, 1974-2006. Soc Psychiatry Psychiatr Epidemiol, DOI 10.1007/s00127-0120499-4

20. Khoo S-E, McDonald P, Giorgas D, Birrell B (2002) Second Generation Australians. Department of Immigration and Multicultural and Indigenous Affairs. http://www.immi.gov.au/media/publications/multicultural/2gen/sg australians.pdf Accessed 25 October 2012

21. Kwak K (2003) Adolescents and their parents: A review of intergenerational family relations for immigrant and non-immigrant families. Hum Dev, 46: 115-136.

22. Large MM, Nielssen OB, Lackersteen SM (2009) The rise and fall of suicide in New South Wales. Med J Aust, 190(5): 282.

23. Mann JJ, Apter A, Bertolote J, Beautrais A, Currier D, Haas A, et al. (2005) Suicide prevention strategies: a systematic review. JAMA, 294: 2064-2074 
24. Marmot MG, Adelstein AM, Bulusu L (1984) Lessons from the study of immigrant mortality. Lancet, 323: 1455-1457

25. McDonald B, Steel Z (1997) Immigrants and mental health: an epidemiological analysis. Transcultural Mental Health Centre: Sydney

26. Morrell S, Taylor R, Slaytor E, Ford P (1999) Urban and rural suicide differentials in migrants and the Australian-born, New South Wales, Australia 1985-1994. Soc Sci Med, 49: 81-91

27. Nasseri K, Moulton LH (2011) Patterns of Death in the First and Second Generation Immigrants from Selected Middle Eastern Countries in California. J Immigr Minor Health, 13: 361-370

28. Nielssen OB, Malhi GS, McGorry PD, Large MM (2012) Overview of violence to self and others during the first episode of psychosis. J Clin Psychiatry, 73(5):e580-7. doi: 10.4088/JCP.11r07036.

29. Noh E (2010) Suicide. In: Chen E.W.C. and Yoo G.J. (eds.) Encyclopaedia of Asian American Issues Today, Volume 1.Greenwood Press, Santa Barbara, pp.373-385. http://books.google.com.au/books?id=R t3yQiWKQEC\&pg=PA377\&lpg=PA377\&dq=Interge nerational+Acculturation+Conflict+Model+elderly+immigrants\&source=bl\&ots=sPjN288eaY \&sig=48uQLNRLEWW dRpmXjUOOTbXNjw\&hl=en\&sa=X\&ei=BKRGUbHWAon8IAXQ04FY\&ve $\mathrm{d}=0 \mathrm{CHcQ} 6 \mathrm{AEwCDgK \# v=onepage \& q=Intergenerational \% 20Acculturation} \% 20$ Conflict\%20Mod el\%20elderly\%20immigrants\&f=false Assessed 18 March 2012

30. National Coronial Information System (2012) Official website of the National Coronial Information System. http://www.ncis.org.au/ Accessed 25 October 2012

31. Peña JB, Wyman PA, Brown CH, Matthieu MM, Olivares TE, Hartel D, Zayas LH (2008) Immigration generation status and its association with suicide attempts, substance use, and depressive symptoms among latino adolescents in the USA. Prev Sci, 9(4):299-310. doi: 10.1007/s11121-008-0105-x

32. Szapocznik J, Kurtines W (1980). Acculturation, biculturalism, and adjustment among Cuban Americans. In A. Padilla (ed) Acculturation: Theory, models, and some new findings. Westview, Boulder, CO, pp 139-159

33. Szapocznik J, Kurtines W, Fernandez T (1980). Biculturalism involvement and adjustment in Hispanic-American youths. Int J Intercult Rel, 4: 353-365Whitlock FA (1971) Migration and suicide. Med J Aust, 23: 840-848 
34. Whitlock FA (1971) Migration and suicide. Med J Aust, 23: 840-848.

35. World Health Organization (2006) Pesticides are a leading suicide method.

http://www.who.int/mediacentre/news/notes/2006/np24/en/index.html Accessed 4 March 
Figure 1: Data collection and linkage and immigrant generation status definition procedure

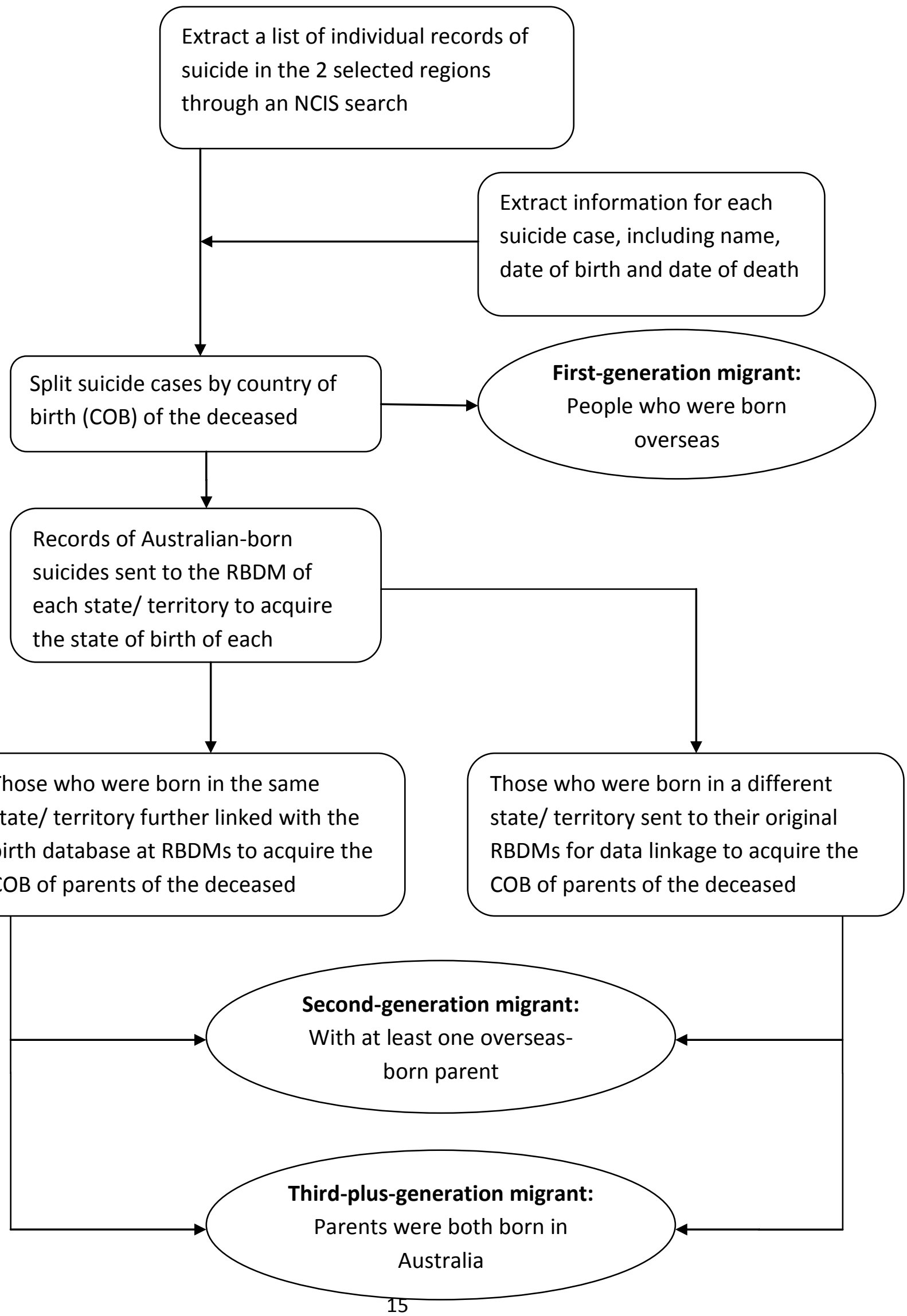


Figure 2: Number and distribution of linked suicide cases by order of immigrant generation in the Australian Capital Territory and New South Wales, 2001-2008

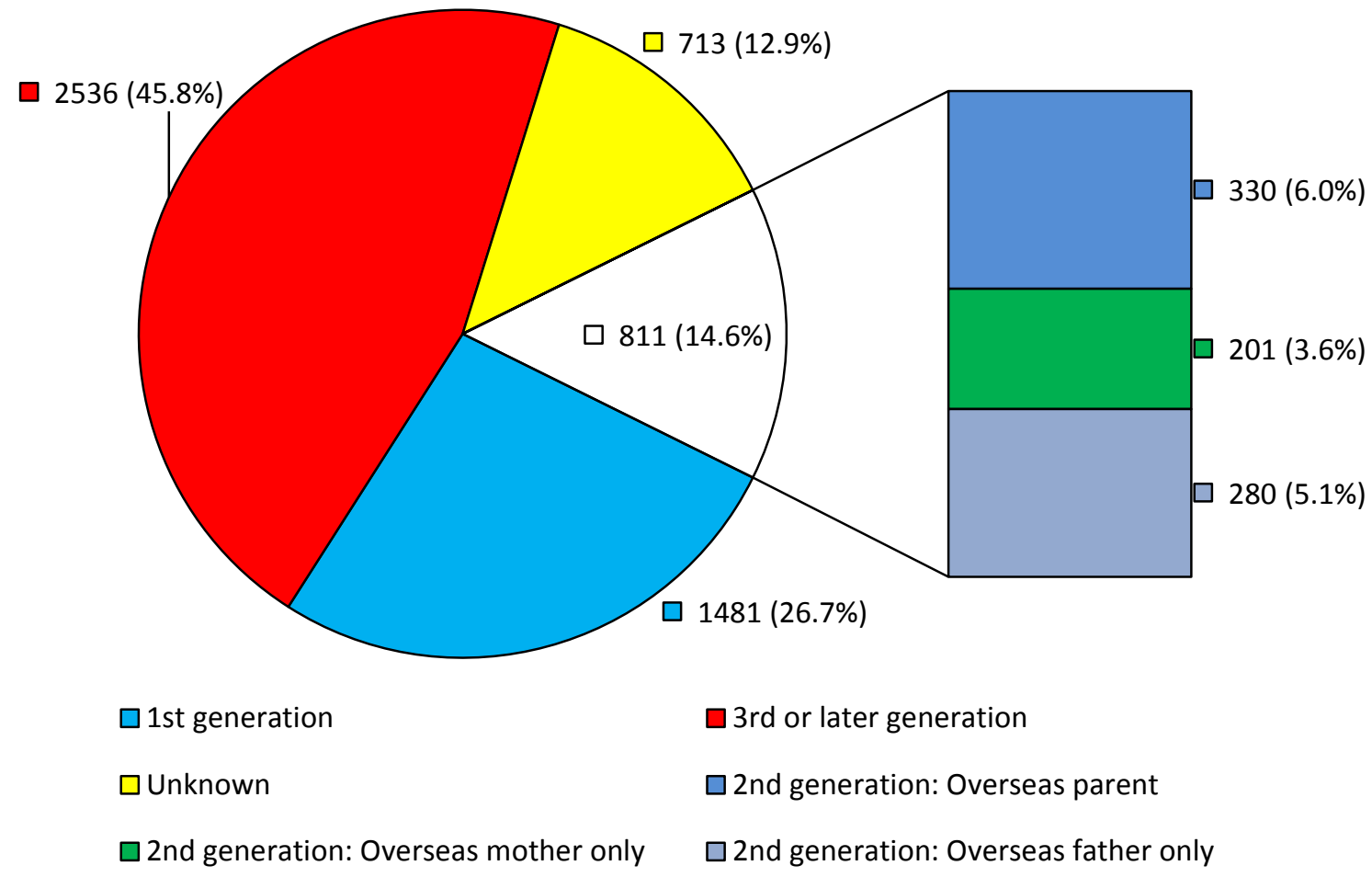


Table 1: Characteristics of suicide cases in second-generation migrants and other migrant generations,

Australian Capital Territory (ACT) and New South Wales (NSW), Australia, 2001-2008

\begin{tabular}{|c|c|c|c|c|c|c|c|c|c|c|c|c|c|c|c|}
\hline & & \multicolumn{2}{|c|}{ Second generation } & \multicolumn{6}{|c|}{ First generation } & \multicolumn{6}{|c|}{ Third-plus generation } \\
\hline & & $\mathrm{N}$ & $\%$ & $\mathrm{~N}$ & $\%$ & $O R^{a}$ & $\begin{array}{l}95 \% \\
\mathrm{LL}\end{array}$ & $\begin{array}{l}95 \\
\mathrm{UL}\end{array}$ & $\begin{array}{r}p- \\
\text { value }\end{array}$ & $\mathrm{N}$ & $\%$ & $\mathrm{OR}^{\mathrm{b}}$ & $\begin{array}{l}95 \% \\
\mathrm{LL}\end{array}$ & $\begin{array}{l}95 \\
\mathrm{UL} \\
\end{array}$ & $\begin{array}{r}p- \\
\text { value }\end{array}$ \\
\hline Sex & Male & 634 & 78.2 & 1107 & 74.7 & 1.21 & 0.99 & 1.48 & 0.066 & 2038 & 80.4 & 0.88 & 0.72 & 1.06 & 0.177 \\
\hline Age & Below 40 & 493 & 60.8 & 477 & 32.2 & 3.26 & 2.73 & 3.90 & $<0.001$ & 1159 & 45.7 & 1.84 & 1.57 & 2.16 & $<0.001$ \\
\hline \multirow{3}{*}{$\begin{array}{l}\text { Marital } \\
\text { status }\end{array}$} & Never married & 426 & 52.5 & 456 & 30.8 & 2.50 & 2.08 & 2.97 & $<0.001$ & 1124 & 44.3 & 1.40 & 1.19 & 1.63 & $<0.001$ \\
\hline & $\begin{array}{l}\text { Married } \\
\text { Divorce, separated \& }\end{array}$ & 231 & 28.8 & 663 & 44.8 & 0.50 & 0.41 & 0.59 & $<0.001$ & 829 & 32.7 & 0.80 & 0.69 & 0.98 & 0.025 \\
\hline & widowed & 128 & 15.8 & 304 & 20.5 & 0.70 & 0.58 & 0.91 & 0.006 & 520 & 20.5 & 0.70 & 0.59 & 0.90 & 0.003 \\
\hline \multirow{3}{*}{$\begin{array}{l}\text { Employment } \\
\text { status }\end{array}$} & Employed & 340 & 42.6 & 584 & 39.4 & 1.10 & 0.93 & 1.32 & 0.245 & 1112 & 44 & 0.90 & 0.79 & 1.08 & 0.336 \\
\hline & Unemployed & 178 & 21.2 & 246 & 16.6 & 1.40 & 1.14 & 1.75 & 0.002 & 520 & 19.9 & 1.10 & 0.90 & 1.32 & 0.379 \\
\hline & Economically inactive & 241 & 29.7 & 574 & 38.8 & 0.70 & 0.56 & 0.80 & $<0.001$ & 851 & 30 & 1.00 & 0.85 & 1.19 & 0.955 \\
\hline Usual & Sydney & 512 & 65.9 & 1118 & 79.9 & 0.60 & 0.49 & 0.72 & $<0.001$ & 1184 & 48.7 & 2.03 & 1.72 & 2.40 & $<0.001$ \\
\hline residence & Newcastle & 70 & 9 & 58 & 4.1 & 2.04 & 1.45 & 2.87 & $<0.001$ & 291 & 12 & 0.75 & 0.57 & 0.98 & 0.034 \\
\hline (NSW only) & Rest of NSW & 195 & 25.1 & 223 & 15.9 & 1.43 & 1.17 & 1.76 & 0.001 & 955 & 39.3 & 0.51 & 0.43 & 0.61 & $<0.001$ \\
\hline Suicide & Poisoning & 202 & 24.9 & 322 & 21.7 & 1.19 & 0.98 & 1.46 & 0.085 & 712 & 28.1 & 0.85 & 0.71 & 1.02 & 0.078 \\
\hline \multirow{4}{*}{ method } & Hanging & 387 & 47.7 & 701 & 47.3 & 1.02 & 0.86 & 1.21 & 0.86 & 1174 & 46.3 & 1.06 & 0.90 & 1.24 & 0.479 \\
\hline & Firearm & 56 & 6.9 & 83 & 5.6 & 1.25 & 0.88 & 1.77 & 0.213 & 248 & 9.8 & 0.68 & 0.51 & 0.93 & 0.014 \\
\hline & Jumping & 67 & 8.3 & 137 & 9.3 & 0.88 & 0.65 & 1.20 & 0.427 & 111 & 4.4 & 1.97 & 1.44 & 2.69 & $<0.001$ \\
\hline & Drowning & 9 & 1.1 & 62 & 4.2 & 0.26 & 0.13 & 0.52 & $<0.001$ & 38 & 1.5 & 0.74 & 0.36 & 1.53 & 0.415 \\
\hline
\end{tabular}


Table 2: Suicide rate (aged $15+$ ) by migrant generation and incidence risk ratio of suicide of second-generation migrants when compared with other migrant generations, Australian Capital Territory (ACT) and New South Wales (NSW), Australia, 2001-2008

\begin{tabular}{|c|c|c|c|c|c|c|c|c|c|c|c|c|c|c|c|}
\hline & & \multicolumn{2}{|c|}{$\begin{array}{l}\text { Second- } \\
\text { generation }\end{array}$} & \multicolumn{6}{|c|}{ First-generation } & \multicolumn{6}{|c|}{ Third-plus-generation } \\
\hline & & & licide rate & \multicolumn{3}{|c|}{ Suicide rate } & \multirow{2}{*}{$\begin{array}{c}\text { ation } \\
95 \% \\
\text { LL } \\
\end{array}$} & \multirow{2}{*}{$\begin{array}{c}95 \% \\
\text { UL }\end{array}$} & \multirow{2}{*}{$\begin{array}{c}\mathrm{p}- \\
\text { value }\end{array}$} & \multicolumn{3}{|c|}{ Suicide rate } & \multirow{2}{*}{$\begin{array}{l}95 \% \\
\mathrm{LL} \\
\end{array}$} & \multirow{2}{*}{$\begin{array}{l}95 \% \\
\text { UL }\end{array}$} & \multirow{2}{*}{$\begin{array}{c}\mathrm{p}- \\
\text { value }\end{array}$} \\
\hline & & $\mathrm{N}$ & a & $\mathrm{N}$ & a & $\mathrm{IRR}^{\mathrm{b}}$ & & & & $\mathrm{N}$ & a & $\mathrm{IRR}^{\mathrm{c}}$ & & & \\
\hline \multirow[t]{5}{*}{ Male } & $15-24$ & 117 & 11.6 & 78 & 11.5 & 1.010 & 0.758 & 1.345 & 0.948 & 259 & 12.5 & 0.935 & 0.752 & 1.163 & 0.548 \\
\hline & $25-39$ & 276 & 21.4 & 284 & 17.4 & 1.230 & 1.042 & 1.452 & 0.014 & 691 & 25.3 & 0.848 & 0.738 & 0.975 & 0.021 \\
\hline & $40-59$ & 168 & 18.3 & 418 & 16.4 & 1.118 & 0.935 & 1.338 & 0.221 & 749 & 18.9 & 0.969 & 0.820 & 1.145 & 0.71 \\
\hline & $60+$ & 70 & 13.1 & 325 & 19.3 & 0.681 & 0.526 & 0.881 & 0.004 & 330 & 13.5 & 0.978 & 0.756 & 1.266 & 0.865 \\
\hline & $15+$ & 634 & 16.9 & 1,105 & 16.9 & $1.016^{\mathrm{d}}$ & 0.920 & 1.122 & 0.755 & 2,029 & 18.1 & $0.927^{d}$ & 0.847 & 1.014 & 0.099 \\
\hline \multirow[t]{5}{*}{ Female } & $15-24$ & 34 & 3.5 & 25 & 3.7 & 0.937 & 0.559 & 1.570 & 0.805 & 61 & 3.1 & 1.140 & 0.749 & 1.734 & 0.541 \\
\hline & $25-39$ & 62 & 4.8 & 86 & 4.9 & 0.969 & 0.699 & 1.344 & 0.852 & 138 & 4.9 & 0.969 & 0.718 & 1.307 & 0.836 \\
\hline & $40-59$ & 50 & 5.4 & 143 & 5.4 & 0.997 & 0.722 & 1.375 & 0.984 & 198 & 4.9 & 1.105 & 0.810 & 1.507 & 0.529 \\
\hline & $60+$ & 30 & 4.5 & 118 & 6.8 & 0.661 & 0.443 & 0.987 & 0.043 & 100 & 3.3 & 1.384 & 0.921 & 2.082 & 0.118 \\
\hline & $15+^{d}$ & 176 & 4.6 & 372 & 5.5 & $0.876^{d}$ & 0.730 & 1.050 & 0.153 & 497 & 4.2 & $1.122^{d}$ & 0.943 & 1.334 & 0.194 \\
\hline
\end{tabular}

